\title{
Balloon pulmonary valvuloplasty in carcinoid syndrome
}

\author{
O Obel, D J Coltart, M Signy
}

Cardiothoracic

Centre, Guy's and St

Thomas Hospital NHS

Trust, London, UK

O Obel

D J Coltart

M Signy

Correspondence to:

Dr Owen Obel, Department of Cardiology, Royal Sussex County Hospital, Eastern Road, Brighton BN2 5BE, UK

oobel@hotmail.com

Accepted 6 September 2000

\begin{abstract}
Half of all patients with carcinoid syndrome develop cardiac involvement. Patients who have cardiac involvement have a significantly worse prognosis than those without, and death can occur directly as a result of cardiac involvement. A case of carcinoid syndrome in a 38 year old woman with lesions in the liver, who presented with right sided valvar abnormalities, a dilated right ventricle, and right ventricular pressure overload, is presented. In order to palliate the patient's symptoms and to decrease right sided pressures before major abdominal surgery, balloon pulmonary valvuloplasty was performed at the time of cardiac catheterisation. This resulted in a reduction in the pulmonary gradient and right ventricular pressure. Following the procedure, the patient's symptoms were completely relieved. She went on to laparotomy where the lesions in the liver were excised without complication. (Heart 2000;84:e13)
\end{abstract}

Keywords: carcinoid syndrome; balloon pulmonary valvuloplasty

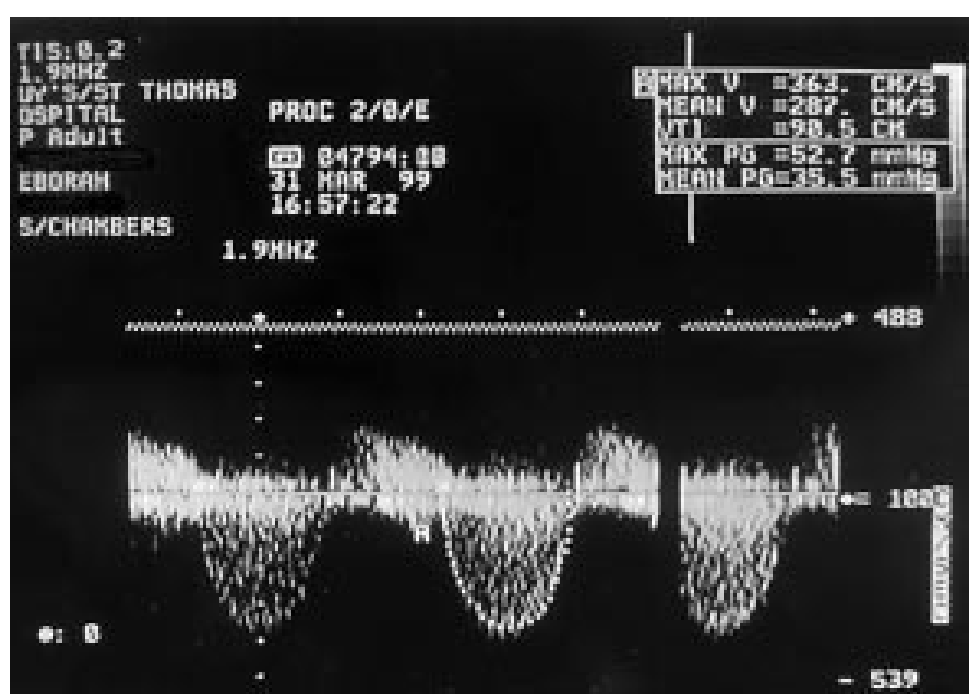

Figure 1 Continuous wave Doppler through the pulmonary valve at transoesophageal echocardiography. A peak instantaneous gradient of $52.7 \mathrm{~mm} \mathrm{Hg}^{-1}$ is present. This gradient was reduced to $8 \mathrm{~mm} \mathrm{Hg}^{-1}$ after balloon pulmonary valvuloplasty.
A 38 year old woman presented with a history of shortness of breath on exertion for the past month, one week of ankle swelling, and a dry cough. She reported bouts of intermittent diarrhoea, palpitations, and facial flushing for the preceding two years. On examination she had prominent violaceous facial flushing, sinus tachycardia of 120 beats/min, raised jugular venous pressure, mild ankle oedema, and a $2 / 6$ ejection systolic murmur at the left sternal edge. The liver was smoothly enlarged $4 \mathrm{~cm}$ below the costal margin. Transthoracic and later transoesophageal echocardiography revealed severe pulmonary infundibular stenosis with a minimum diameter of $1.6 \mathrm{~cm}$, poststenotic dilatation of $3 \mathrm{~cm}$, and a peak instantaneous gradient across the pulmonary valve of $52.7 \mathrm{~mm} \mathrm{Hg}^{-1}$ (fig 1). Moderate pulmonary regurgitation was also present. Thickened tricuspid valve tips and reduced septal diastolic leaflet motion associated with moderate tricuspid regurgitation were noted. The right ventricle was dilated and there was evidence of right ventricular pressure overload. Right heart catheterisation revealed markedly increased right ventricular pressures (55/ $8 \mathrm{~mm} \mathrm{Hg}^{-1}$ ), grade 2 tricuspid regurgitation, and the gradient across the pulmonary valve was confirmed. Narrowing at the level of the pulmonary infundibulum was noted (fig 2). Abdominal ultrasonography revealed a large

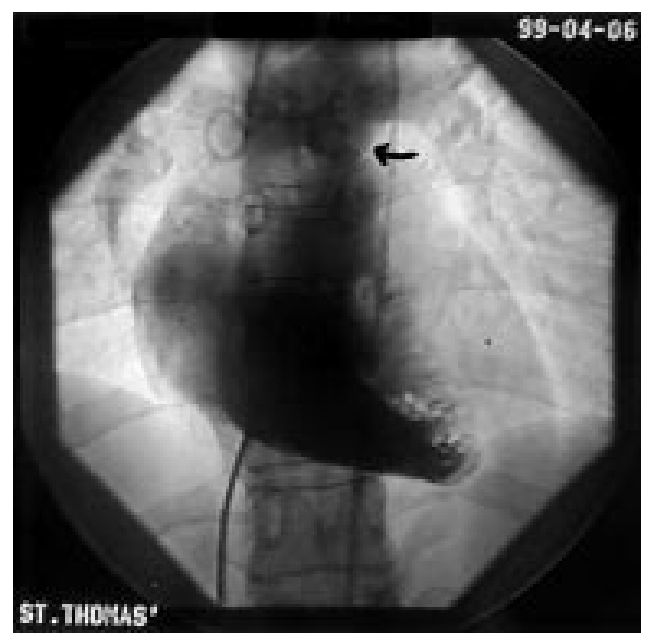

Figure 2 Right heart angiography reveals pronounced narrowing at the level of the pulmonary infundibulum (arrow) before valvuloplasty which was performed during the same session. 
irregular echogenic mass in the left lobe and smaller lesions within the right lobe of the liver. Urinary concentrations of 5-hydroxyindoleacetic acid (5-HIAA) and 5-hydroxytryptamine were notably raised suggesting a diagnosis of neuroendocrine tumour associated with carcinoid syndrome as a basis for the right sided valvar abnormalities.

In order to palliate the patient's symptoms and to decrease right sided pressures before major abdominal surgery, balloon pulmonary valvuloplasty was performed at the time of cardiac catheterisation. This resulted in a reduction in the pulmonary gradient from $52 \mathrm{~mm} \mathrm{Hg}^{-1}$ to $8 \mathrm{~mm} \mathrm{Hg}^{-1}$ and a reduction from $55 / 8$ to $31 / 7 \mathrm{~mm} \mathrm{Hg}^{-1}$ in right ventricular pressure.

Following the procedure, the patient's symptoms were completely relieved. She went on to laparotomy where a $12 \mathrm{~cm}$ lesion was found occupying the left lateral segment of the liver. In addition, a small lesion in the antimesenteric border of the ileum associated with a mass of lymph nodes was discovered. A left lateral segmentectomy of the hepatic mass along with a cholecystectomy and a small bowel resection were performed without complication.

\section{Discussion}

Approximately $50 \%$ of patients with carcinoid syndrome develop cardiac involvement. $\mathrm{Pa}-$ tients who have cardiac involvement have a significantly worse prognosis than those without, and death can occur directly as a result of cardiac involvement.

Carcinoid heart disease usually manifests as right sided valvar heart pathology. ${ }^{1}$ The tricuspid valve is involved in almost all patients. Thickened, shortened, immobile tricuspid leaflets result in tricuspid regurgitation, which is often severe. Less commonly, flow limiting tricuspid stenosis occurs which is usually moderate in severity. Pulmonary valve abnormalities occur in approximately $90 \%$ of patients with carcinoid heart disease. Like the tricuspid valve, the pulmonary valve is thickened and retracted resulting usually in pulmonary regurgitation, but stenosis also occurs. Left sided valvar involvement occurs much less frequently. The right atrial wall is thickened when compared to the left atrial wall, particularly in patients with right sided valvar disease. Occasionally myocardial metastases, pericardial effusions, and constrictive pericarditis can occur.

Patients with cardiac involvement generally have higher concentrations of urinary 5-HIAA, suggesting a causal role for serotonin and other circulating vasoactive substances in the pathogenesis of cardiac involvement ${ }^{1}$; however, this is still speculative. Despite these observations, significant reductions in the concentrations of 5-HIAA with treatment are not usually associated with regression of the cardiac abnormalities. ${ }^{2}$

Treatment options for patients with carcinoid heart disease include medical treatment, surgery or interventional catheter techniques.
Medical treatment consists of vasodilator and diuretic therapy. Surgical treatment with valve replacement has been performed in small numbers of patients with carcinoid heart disease. ${ }^{34}$ Reports from these small series consistently show a high perioperative morbidity and mortality. ${ }^{34}$ Balloon valvuloplasty has been previously used in the treatment of carcinoid valvar heart disease involving both the pulmonary and tricuspid valves. ${ }^{5-7}$ Reports on this form of treatment in single or very small numbers of patients quote variable success rates. While some authors report rapid relapse of valvar stenosis, ${ }^{6}$ other patients appear to have experienced lasting benefit from balloon valvuloplasty, particularly when combined with aggressive medical treatment. ${ }^{5}$

The patient presented in this report was highly symptomatic from severe pulmonary stenosis which was resulting in raised right sided pressures. The decision to perform balloon valvuloplasty was made for two reasons. First, the patient's symptoms from the pulmonary outflow obstruction were severe enough to limit her exercise capacity to 20 yards on the flat and it was felt that immediate relief of these symptoms was warranted. Furthermore, it was felt that the high right sided pressures would increase the likelihood of major bleeding during surgery, and that by relieving the right sided outflow obstruction, this risk could be significantly reduced. One report describes cardiac surgery as a means of reducing postsinusoidal portal hypertension in a patient who required debulking of carcinoid hepatic metastases. ${ }^{8}$

This is the first report of the use of balloon valvuloplasty as a strategy to reduce right sided pressures in carcinoid valvar heart disease associated with resectable hepatic metastases, and in this case the strategy was successful. We conclude that balloon pulmonary valvuloplasty can be used as both a palliative procedure in patients with symptomatic pulmonary stenosis associated with carcinoid, and as an enabling procedure, reducing the risk of perioperative abdominal bleeding in the presence of very high right sided pressures.

1 Pellikka PA, Tajik AJ, Khandheria BK, et al. Carcinoid heart disease. Clinical and echocardiographic spectrum in 74 patients. Circulation 1993;87:1188-96.

2 Denney WD, Kemp WEJ, Anthony LB, et al. Echocardiographic and biochemical evaluation of the development and progression of carcinoid heart disease. $7 \mathrm{Am}$ Coll Cardiol 1998;32:1017-22.

3 Robiolio PA, Rigolin VH, Harrison JK, et al. Predictors of outcome of tricuspid valve replacement in carcinoid heart disease. Am F Cardiol 1995;75:485-8.

4 Connolly HM, Nishimura RA, Smith HC, et al. Outcome of cardiac surgery for carcinoid heart disease. $7 \mathrm{Am}$ Coll Cardiol 1995;25:410-16.

5 Hargreaves AD, Pringle SD, Boon NA. Successful balloon dilatation of the pulmonary valve in carcinoid heart disease. Int f Cardiol 1994;45:150-1.

6 Grant SC, Scarffe JH, Levy RD, et al. Failure of balloon dilatation of the pulmonary valve in carcinoid pulmonary stenosis. Br Heart f 1992;67:450-3.

7 Onate A, Alcibar J, Inguanzo R, et al. Balloon dilation of tricuspid and pulmonary valves in carcinoid heart disease. Texas Heart Institute fournal 1993;20:115-19.

8 McDonald ML, Nagorney DM, Connolly HM, et al. Carcinoid heart disease and carcinoid syndrome: successful surgical treatment. Ann Thorac Surg 1999;67:537-9. 